\title{
Solution to Phosphine NMR challenge
}

\section{Andryj M. Borys ${ }^{1}$}

Accepted: 3 February 2021 / Published online: 9 April 2021

(C) Springer-Verlag GmbH Germany, part of Springer Nature 2021

The winner of the Phosphine NMR challenge (published in volume 412 issue 25) is:

Andreu Tortajada Navarro, Catalan Institute of Chemical Research, Tarragona, Spain

The award entitles the winner to select a Springer book of his choice up to a value of $€ 100,-$.

Our Congratulations!

This Analytical Challenge [1] invites you to explore the effects of isotopic substitution on the NMR spectra for $\mathrm{PH}_{3}$ and $\mathrm{PD}_{3}$. For $\mathrm{PH}_{3}$, containing three equivalent ${ }^{1} \mathrm{H}$ atoms with nuclear spin $I=1 / 2$, a binomial quartet with intensity ratios of 1:3:3:1 is observed in the ${ }^{31} \mathrm{P}$ NMR spectrum (Fig. 1).

For $\mathrm{PD}_{3}$, containing three equivalent ${ }^{2} \mathrm{H}$ atoms with nuclear spin $I=1$, a more complex non-binomial septet with intensity ratios of $1: 3: 6: 7: 6: 3: 1$ is observed in the ${ }^{31} \mathrm{P}$ NMR spectrum (Fig. 2).

For a given pair of elements, the scalar coupling constant is proportional to the product of the gyromagnetic ratios of the nuclei provided all other factors remain the same. Given that the ${ }^{1} J_{\mathrm{P}-\mathrm{H}}$ coupling constant in $\mathrm{PH}_{3}$ is ${ }^{1} J_{\mathrm{P}-\mathrm{H}}=187.8 \mathrm{~Hz}$, the ${ }^{1} J_{\mathrm{P}-\mathrm{D}}$ coupling constant in $\mathrm{PD}_{3}$ can be obtained. The gyromagnetic ratio of ${ }^{1} \mathrm{H}$ is $\gamma\left({ }^{1} \mathrm{H}\right)=26.75 \times 10^{7} \mathrm{rad} \mathrm{T}^{-1} \mathrm{~s}^{-1}$ and for ${ }^{2} \mathrm{H}$ is $\gamma\left({ }^{2} \mathrm{H}\right)=4.107 \times 10^{7} \mathrm{rad} \mathrm{T}^{-1} \mathrm{~s}^{-1}$, thus giving a ratio $\gamma\left({ }^{1} \mathrm{H}\right) /$ $\gamma\left({ }^{2} \mathrm{H}\right)=6.5$. Dividing the ${ }^{1} J_{\mathrm{P}-\mathrm{H}}$ coupling constant in $\mathrm{PH}_{3}$ by this ratio gives a predicted ${ }^{1} J_{\mathrm{P}-\mathrm{D}}$ coupling constant of ${ }^{1} J_{\mathrm{P}-\mathrm{D}}=$ $28.8 \mathrm{~Hz}$ for $\mathrm{PD}_{3}$ which compares well with the experimentally measured value of $29.3 \mathrm{~Hz}$ [2].
This article is the solution to the Analytical Challenge to be found at https://doi.org/10.1007/s00216-020-02880-6

Andryj M. Borys

andryjmborys@gmail.com

1 Department of Chemistry and Biochemistry, University of Bern, Freiestrasse 3, 3012 Bern, Switzerland 
Fig. $1{ }^{31} \mathrm{P}$ NMR spectrum of $\mathrm{PH}_{3}$, showing a quartet whose intensities can be viewed as binomial coefficients of $(1+x)^{3}$ expansion: $1 x^{0}+3 x^{1}+3 x^{2}+1 x^{3}$

Fig. $2{ }^{31} \mathrm{P}$ NMR spectrum of $\mathrm{PD}_{3}$, showing a septet whose intensities can be viewed as trinomial coefficients of $(1+x+$ $\left.x^{2}\right)^{3}$ expansion: $1 x^{0}+3 x^{1}+6 x^{2}+$ $7 x^{3}+6 x^{4}+3 x^{5}+1 x^{6}$
${ }^{31}$ P NMR
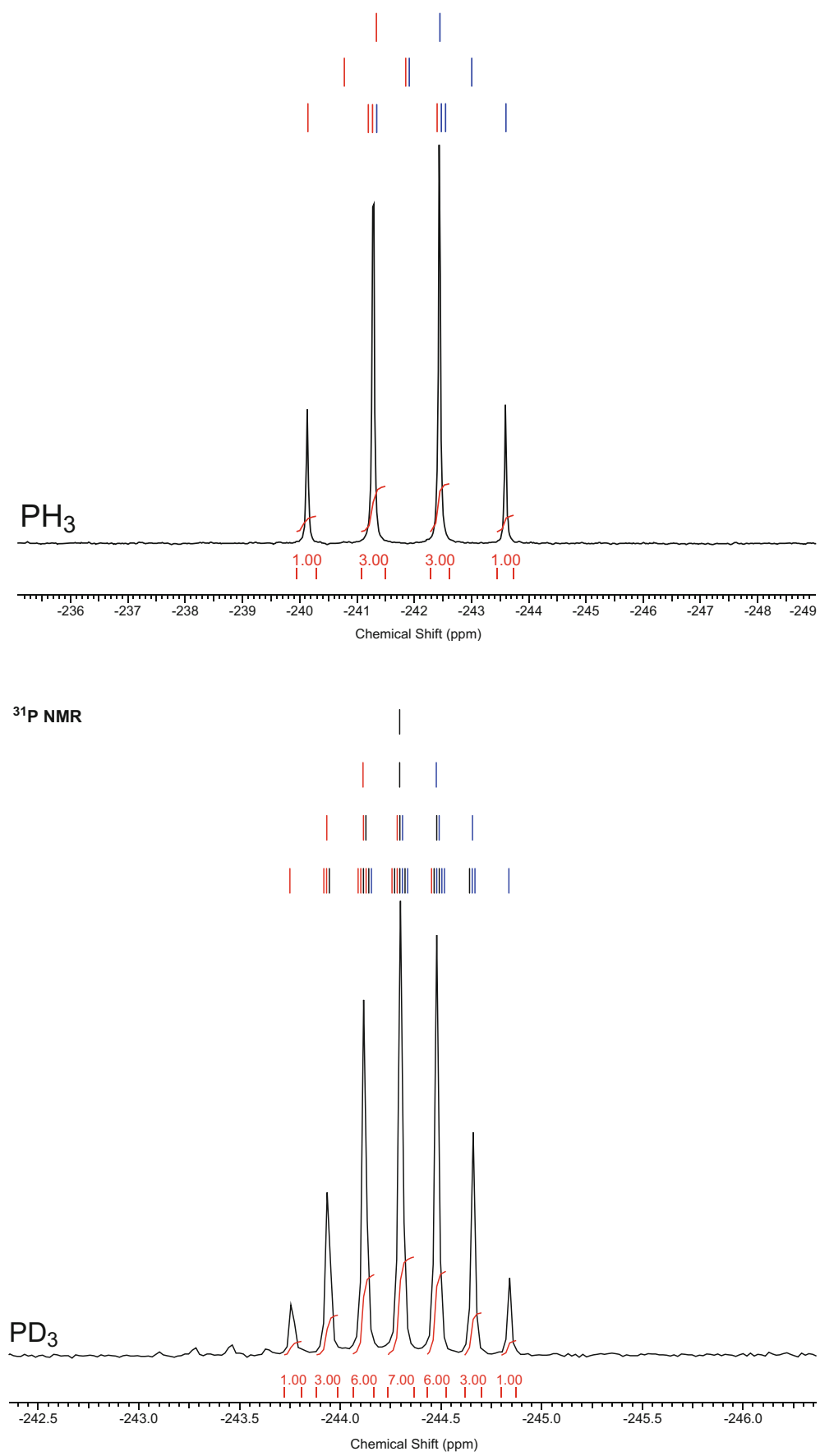

\section{Declarations}

2. Bhattacharyya KX, Dreyfuss S, Saffon-Merceron N, Mezailles N. Chem Commun. 2016;52:5179-82. https://doi.org/10.1039/ C6CC01683A.

Publisher's note Springer Nature remains neutral with regard to jurisdictional claims in published maps and institutional affiliations.

\section{References}

1. Borys AM. Phosphine NMR challenge. Anal Bioanal Chem. 2020;412:6633-4. https://doi.org/10.1007/s00216-020-02880-6. 